\title{
Microstructure and Mechanical Properties of Annealed Quinary Ni-Mn-Sn-Fe-In Heusler Alloy
}

\author{
Sandeep Nambiar S., ${ }^{1}$ BRN. Murthy, ${ }^{1,}{ }^{*}$ Sathyashankara Sharma, ${ }^{1}$ A. A. Prasanna ${ }^{2}$ and Arout Chelvane J. ${ }^{3}$
}

\begin{abstract}
The tuning of Heusler alloys with respect to stoichiometry and their effect on martensitic transformation has been investigated very little by various researchers. Thus, the effect of change in ferrous (Fe) concentration of the alloys and its effect on mechanical and magnetocaloric properties of $\mathrm{Ni}_{50-x} \mathrm{Fe}_{x} \mathrm{Mn}_{30} \mathrm{Sn}_{20-y} \mathrm{In}_{y}$ alloys were investigated where Fe was varied from $x=1,2,3$, and 4 to find its significance. An increase in Fe concentration to $\mathrm{Fe}_{4}$ leads to a considerable improvement in the alloy's mechanical properties and crystal structure. The compressive strength of the alloy rose by $123 \%$ for Fe 4 substitution. When comparing the identical materials with and without Fe addition, the ultimate stress (US) and ductility are improved by 124 and $200 \%$, respectively, while toughness rises by 48 times. The Fe concentration variation also enabled a martensitic transformation in the 36.8 to $19.83^{\circ} \mathrm{C}$ range of refrigerator applications.
\end{abstract}

Keywords: Heusler alloys; Martensitic transformation; Magnetic refrigeration; Tensile strength; Brittleness.

Received: 08 October 2021; Revised: 10 January 2022; Accepted: 18 January 2021.

Article type: Research article.

\section{Introduction}

Air conditioning and refrigeration are depleting the ozone layer due to the increasing human usage of these technologies. Traditionally, refrigerant gases like chlorofluorocarbons (CFCs) have been used in refrigeration and air conditioning. Over the years, it's been demonstrated that these chemicals contribute significantly to the destruction of the ozone layer. To provide a safer living environment for everyone on the planet, a better cooling system that does not use ozonedepleting gases is required. ${ }^{[1]}$ As an alternative to the present system, magnetic cooling has been devised. In contrast to vapor compression technology, magnetic cooling does not produce hazardous compounds and is thus considered the cooling technology of the future. Magnetic cooling makes use of magnetic materials and employs adiabatic demagnetization to achieve cooling. Magnetic cooling requires the use of a high-intensity magnetic field source coupled with a material capable of withstanding high body temperatures. ${ }^{[2]} \mathrm{A}$ first-

\footnotetext{
${ }^{1}$ Department of Mechanical and Manufacturing Engineering,

Manipal Institute of Technology, Manipal Academy of Higher

Education, Manipal, Karnataka, 576104, India.

${ }^{2}$ Department of Physics, Malnad College of Engineering, Hassan, Karnataka, 573202, India.

${ }^{3}$ Advanced Magnetics Laboratory, Defense Metallurgical Research Laboratory, Kanchanabagh, Hyderabad, Telangana, 500066, India.

*E-mail: murthy.brn@manipal.edu (BRN Murthy)
}

order martensitic transformation occurs in Heusler alloys when the original austenitic phase of the material is sheared, resulting in a martensitic transition of the first order. This alloy's martensitic transition is crucial because the material may retain its properties while undergoing martensitic deformation and then convert back to its austenitic state. The Heusler alloy stochiometric most commonly used is $\mathrm{X}_{2} \mathrm{YZ}$, where $\mathrm{X}$ and $\mathrm{Y}$ are transition-metal elements, and $\mathrm{Z}$ is a maingroup element. ${ }^{[3]}$ Magnetic Heusler alloys can have a memory effect similar to a magnetic shape memory alloy when they are produced. When strain is applied during the martensitic stage, alloys tend to show a significant strain.

Heusler alloys, which are rich in $\mathrm{Ni}$ and $\mathrm{Mn}$, have gained importance ever since their discovery. ${ }^{[4]}$ Continued research on Ni-Mn-In-based alloys where compositional modifications were achieved by the replacement of $\mathrm{Fe}-\mathrm{Sn}$ was of particular interest. ${ }^{[5]}$ In the vast majority of studies, it was discovered that $\mathrm{Ni}$ combining $\mathrm{Mn}$ and $\mathrm{Sn}$ at various compositions has the potential to exhibit favorable properties. ${ }^{[6-12]}$ When the stoichiometry of the compositions is changed, the alloys go through a phase transition from the $\mathrm{L}_{1} 0$ martensitic phase to the L2 1 austenitic phase. ${ }^{[12-14]}$ A variety of applications involving near-room temperature $\left(25-35^{\circ} \mathrm{C}\right)$ use of these alloys are possible because of their magnetocaloric, martensitic, and mechanical characteristics. ${ }^{[15-18]}$ Because of the brittle character of the alloy, it has a limited range of application possibilities. The brittle nature of the alloy results 
in its lower application use. Many researchers have also observed a decrease in the manganese concentration and its influence, as well as a decrease in the magnetic characteristics of the material. ${ }^{[19]}$

The application possibilities of all alloys to undergo the martensitic transition and change at or near ambient temperature are critical. $\mathrm{Ni}_{50-\mathrm{x}} \mathrm{Fe}_{\mathrm{x}} \mathrm{Mn}_{30} \mathrm{Sn}_{20-\mathrm{y}} \mathrm{In}_{\mathrm{y}}$ undergoes martensitic transformations at room temperature. The following alloys were identified as capable of martensitic transition based on their electron atom (e/a) ratio. When there is a drop in the Curie temperature (Tc) accompanied by a small rise in e/a. Above this concentration, the system is martensitic at room temperature (Rt), and then Tc falls quickly as e/a increases. This abrupt change in the e/a dependency of the Curie temperature is ascribed to a difference in the ferromagnetic exchange process between the martensitic and austenitic phases. In the following work, the addition of $\mathrm{Fe}$ to the alloy and its effect on the mechanical characteristics along with the changes in annealed and non-annealed Heusler alloys were studied and correlated.

The novelty of the work is to reduce the processing window of the martensitic transformation temperature to near room temperature by changing the concentration of $\mathrm{Fe}$ and studying its effects on mechanical characteristics. No work has been identified on Ni-Mn-Sn-Fe-In-based quinary heusler alloys and their changes in mechanical characteristics based on tuning the stoichiometry composition.

\section{Materials and methods}

Samples of alloys weighing $5 \mathrm{~g}$ each were created in an argon environment utilizing just a vacuum arc melting furnace in a water-cooled copper $(\mathrm{Cu})$ crucible. All other processes such as sintering and pit furnace melting were avoided when the feasibility and better quality of prepared alloys were considered. After determining the concentrations of $\mathrm{Ni}, \mathrm{Mn}$, $\mathrm{Fe}, \mathrm{Sn}$, and In (99\%), the alloying elements were weighed in accordance with the stoichiometry previously determined. The electron per atom (e/a) ratio, which is quintessential in tuning the martensitic transformation, was determined. Here, the valence electrons per atom for nickel, manganese, tin, iron, and indium are $10,7,4,8$, and 3, respectively, and the atomic weight percentage is indicated as at $\%$ as seen in Equation (1). Electron concentrations in the outer shells can be calculated according to Equation (1). This helps in maintaining the composition of the alloy systems near room temperature and keeps the e/a of the alloy between $7.80-7.70$ such that it shows near room temperature martensitic transformation.

$$
\mathrm{e} / \mathrm{a}=\frac{10 \mathrm{x}(\mathrm{Ni} \text { at. } \%)+7 \mathrm{x}(\mathrm{Mn} \text { at. } \%)+4 \mathrm{x}(\mathrm{Sn} \text { at. } \%)+8 \mathrm{x}(\mathrm{Fe} \text { at. } \%)+3 \mathrm{x}(\mathrm{In} \text { at. } \%)}{100}
$$

The vacuum unit of the furnace system is composed of rotary and diffusion pumps, capable of producing vacuums up to 106 mbar. After the alloys are melted fully, they are hardened to avoid being re-melt and followed by the tweezer mechanism utilized to re-melt the crystals. To ensure the specimen's compositional homogeneity, the melting, solidification, turning over, and final re-melting operations were repeated four times.

$\mathrm{Ni}_{49} \mathrm{Fe}_{1} \mathrm{Mn}_{30} \mathrm{Sn}_{18} \mathrm{In}_{2}, \quad \mathrm{Ni}_{48} \mathrm{Fe}_{2} \mathrm{Mn}_{30} \mathrm{Sn}_{16} \mathrm{In}_{4}, \quad \mathrm{Ni}_{47} \mathrm{Fe}_{3} \mathrm{Mn}_{30^{-}}$ $\mathrm{Sn}_{14} \mathrm{In}_{6}$, and $\mathrm{Ni}_{46} \mathrm{Fe}_{4} \mathrm{Mn}_{30} \mathrm{Sn}_{12} \mathrm{In}_{8}$ alloys were formed when annealed for 48 hours at $750{ }^{\circ} \mathrm{C}$ surface oxidation. Another set of alloys of composition was left as-cast for comparing the results. A section of the alloy was cut and placed on a conventional electron microscopy imaging plate, and a rectangle-shaped specimen was cut from the alloy and used to measure X-ray diffraction (XRD). The XRD patterns from the alloys were recorded using a high-resolution X-ray diffractometer (X'Pert PRO PANalytical) with a filtered $\mathrm{Cu}$ $\mathrm{K} \alpha$ radiation of $0.15410 \mathrm{~nm}$. A curved graphite monochromator was used to run the diffractometer at $40 \mathrm{kV}$ and $30 \mathrm{~mA}$. A continuous $\theta-2 \theta$ scanning was performed across the diffraction angle $2 \theta$ in the $10^{\circ}<2 \theta<90^{\circ}$ range, which covers the range of the typical diffraction peaks. The results were collected at ambient temperature as well as at selected temperatures ranging from 298 to $400 \mathrm{~K}$. The lattice expansion and phase transition of an alloy can be investigated using temperature-dependent experiments. Scan steps were performed on all various alloy samples between diffraction angles 35 and $70^{\circ}$ at a slow scan rate of $0.02 \%$ minute for a predefined time of 2-4 s. The positions of XRD peaks are determined with remarkable precision by using a large time frame and a small angular range. Crystalline phases of various alloy set formed with the standard patterns, and the obtained XRD patterns were compared to those of previously recognized crystalline phases.

Polycrystalline samples weighing $20 \mathrm{mg}$ were cut from the samples for differential scanning calorimetry (DSC) analysis. The test was performed on the specimen after it was grounded using 2500-grit paper to ensure total thermal contact. The measurement was performed in a METTLER-TOLEDO DSC at a cooling and heating temperature of -70 to $127^{\circ} \mathrm{C}$ at a rate of $10{ }^{\circ} \mathrm{C} / \mathrm{min}$. The test was conducted in a fine-air-cooling system. The $20 \mathrm{mg}$ sample was put in the DSC cell after being enclosed in an aluminum cup with a cover.

A high-resolution microscope was used to capture images that were inspected and analyzed in order to study various microscopic features and their distributions. A combination of XRD and field emission scanning electron microscope (FESEM) imaging was done to investigate the microstructure, while FESEM imaging was used to identify the microstructure. The microstructure imaging was done using FESEM Carl ZEISS make Gemini Scanning Electron Microscope (SEM) 300 with a probe current of $3 \mathrm{pA}$ to $20 \mathrm{nA}$. The completed sample was polished using 3-micron and 1-micron diamond sheets, resulting in a mirror-like surface. Numerous research projects and a review of the literature revealed that Heusler alloys (including those with alloys added) should be etched with the Marble's reagent to get the desired microstructure. The reagent formula comprises $10 \mathrm{~g}$ of $\mathrm{CuSO}_{4}, 50 \mathrm{~mL}$ of $\mathrm{HCl}$, $50 \mathrm{~mL}$ of water, and trace quantities of sulfuric acid to increase 
its activity. The samples were etched for 20 seconds following previous studies.

\section{Results and discussions}

\subsection{Microstructure and crystal structure}

After the alloy is formed by repeated remelting, it is annealed for $48 \mathrm{~h}$ at $750{ }^{\circ} \mathrm{C}$. During annealing, diffusion kinematics is triggered at a higher rate, decimating the dendritic structure and forming a well-distributed grain structure. The dark region seen in the SEM is the Mn element as per similar results from previous works. ${ }^{[20]}$ Fig. 1 shows the microstructural changes occurring as a function of time at $750{ }^{\circ} \mathrm{C}$. There is a consolidation of phases seen clearly in SEM images before and after annealing where the multiphase microstructure is converted to single-phase microstructures as shown in Fig. 1. The coarser dendrites seem to be broken and fine grain, welldispersed phases are seen. The dendrites generally show inhomogeneity in the chemical composition at the microscopic level from location to location or dendrites to dendrites. The dendritic structure generally shows inhomogeneity in the properties throughout. The small dark spot shown in SEM corresponds to the Mn-rich phase, which is in accordance with various other works. ${ }^{[19]}$

The composition of the alloy was checked using the energy-dispersive X-ray Spectroscopy (EDS) analysis technique. Table 1 depicts the average composition of the alloy at varying $x$ and $y$ values. The results envisage the homogenous alloying of all four compositions, $\mathrm{Ni}_{50}$ ${ }_{x} \mathrm{Fe}_{\mathrm{x}} \mathrm{Mn}_{30} \mathrm{Sn}_{20-\mathrm{y}} \mathrm{In}_{\mathrm{y}}$, where $1 \leq \mathrm{x} \leq 4$; and $2 \leq \mathrm{y} \leq 8$.

Table 1. EDS results of arc melted $\mathrm{Ni}_{50-\mathrm{x}} \mathrm{Fe}_{\mathrm{x}} \mathrm{Mn}_{30} \mathrm{Sn}_{20-\mathrm{y}} \mathrm{In}_{\mathrm{y}}$ alloy, where $1 \leq \mathrm{x} \leq 4$; and $2 \leq \mathrm{y} \leq 8$.

\begin{tabular}{lllllll}
\hline & & \multicolumn{6}{l}{ Composition (wt\%) } \\
\cline { 3 - 7 } $\mathrm{x}$ & $\mathrm{y}$ & $\mathrm{Ni}$ & $\mathrm{Mn}$ & $\mathrm{Sn}$ & $\mathrm{In}$ & $\mathrm{Fe}$ \\
\hline 1 & 2 & 37.4 & 26.63 & 31.27 & 3.93 & 0.77 \\
2 & 4 & 37.04 & 26.52 & 27.28 & 7.04 & 1.12 \\
3 & 6 & 37.0 & 26.91 & 23.59 & 10.68 & 1.37 \\
4 & 8 & 36.88 & 26.92 & 20.91 & 13.74 & 1.75
\end{tabular}

The values are accurate within $\pm 0.1 \%$ error.
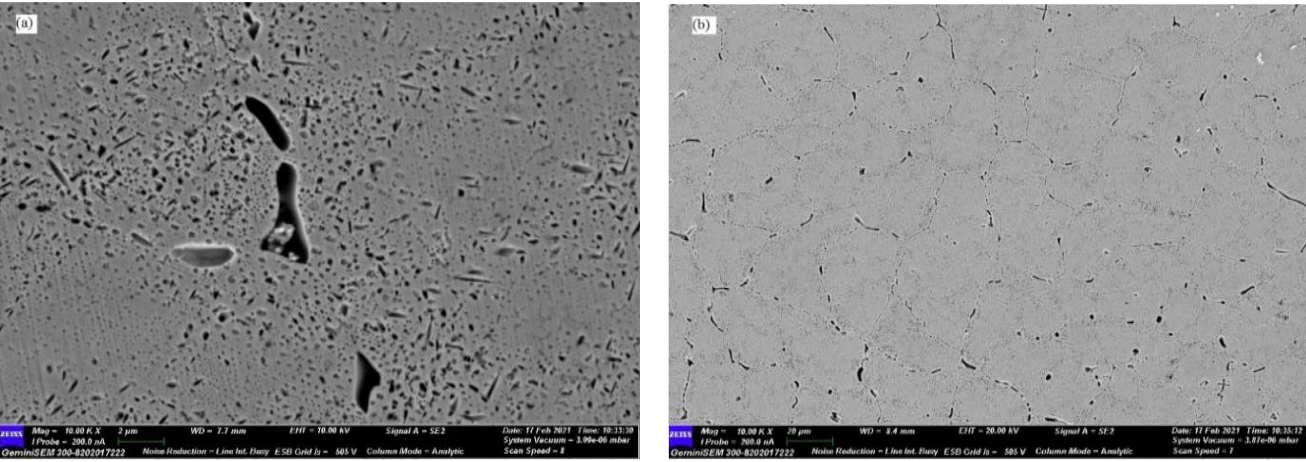

Fig. 1 SEM image showing the effect of heat treatment (a) as-cast; and (b) $48 \mathrm{~h}$ soaking.
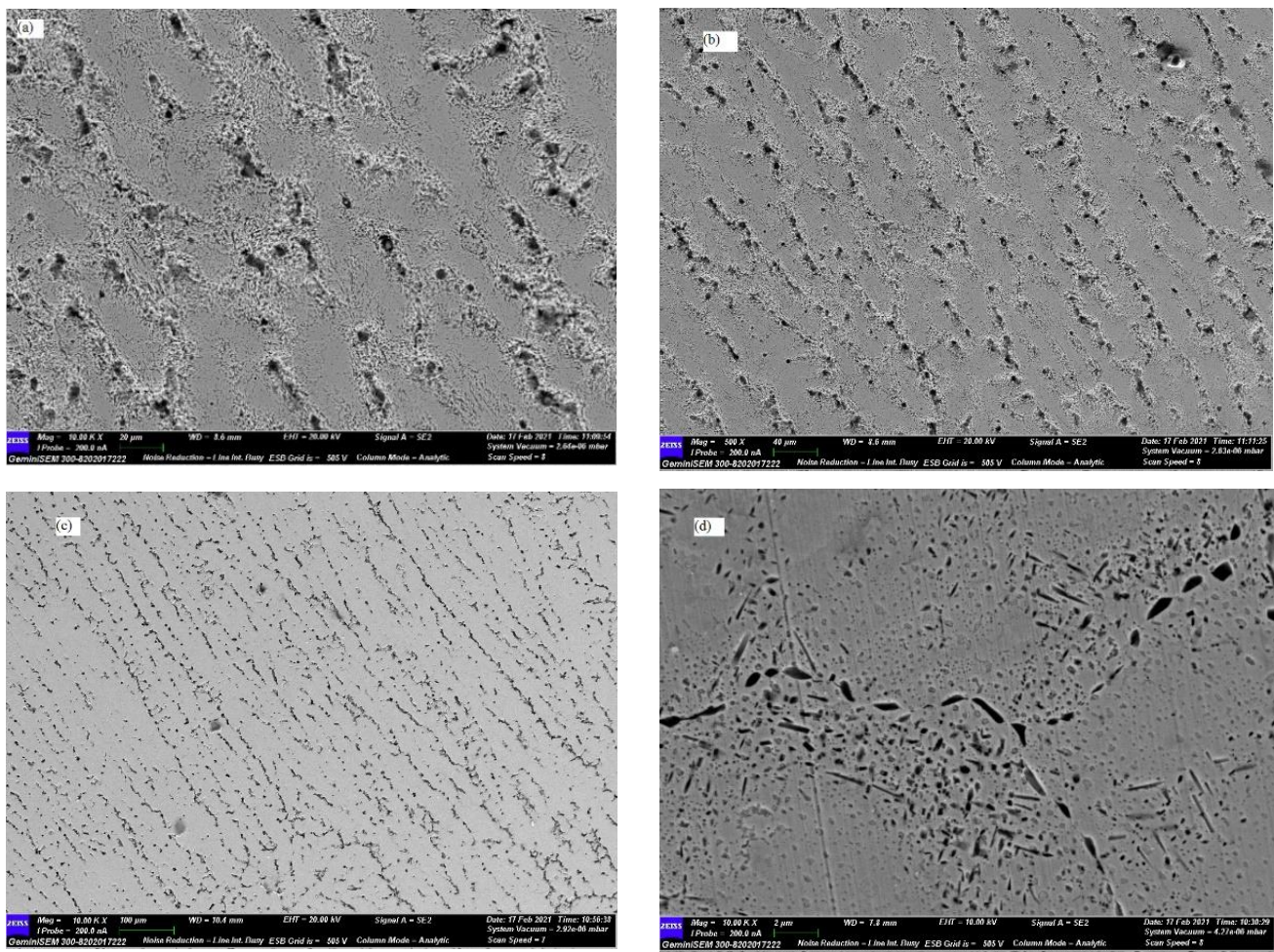

Fig. 2 SEM image of $\mathrm{Ni}_{50-\mathrm{x}} \mathrm{Fe}_{\mathrm{x}} \mathrm{Mn}_{30} \mathrm{Sn}_{20-\mathrm{y}} \mathrm{In}_{\mathrm{y}}$ alloy with (a) $\mathrm{x}=1$; (b) $\mathrm{x}=2$; and (c) $\mathrm{x}=3 ; \mathrm{x}=4$. 
Figure 2 illustrates the variation in the alloy caused by altering the $\mathrm{Fe}$ concentration following a homogenization heat treatment. As noticed originally at $\mathrm{Fe}_{1}$, the spots are shrinkage pores that are commonly produced during the ingot casting. While research indicates that $\mathrm{Fe}_{0}$ and $\mathrm{Fe}_{3}$ have previously demonstrated comparable results. ${ }^{[21]}$ The continuous matrix phase and scattered phase are represented by the light and dark contrasts in $\mathrm{Fe}_{2}, \mathrm{Fe}_{3}$, and $\mathrm{Fe}_{4}$, respectively. The phase's volume increases steadily from $\mathrm{Fe}_{3}$ to $\mathrm{Fe}_{4}$. Fine eutectic microstructures between the Heusler phase (light region) and the $\gamma$ phase (dark region) are being shown. The eutectic structure has a cellular morphology and the solubility of the $\gamma$ phase is reduced and seen that with the increase in $\mathrm{Fe}$ concentration, the $\gamma$ phase also increases. ${ }^{[21]}$

Additionally, the XRD data suggests that the inclusion of $\mathrm{Fe}_{4}$ results in the development of two phases, i.e., a facecentered cubic (FCC) phase and a B2 austenite phase. ${ }^{[22-25]}$ It is clear from the XRD data that the peak intensity rose as the $\mathrm{Fe}$ concentration of the alloy was increased as shown in Fig. 3. (The combined XRD images of specimens A, B, C, and D are given in Fig. S1, where it represents $\mathrm{Ni}_{49} \mathrm{Fe}_{1} \mathrm{Mn}_{30} \mathrm{Sn}_{18} \mathrm{In}_{2}$, $\mathrm{Ni}_{48} \mathrm{Fe}_{2} \mathrm{Mn}_{30} \mathrm{Sn}_{16} \mathrm{In}_{4}, \mathrm{Ni}_{47} \mathrm{Fe}_{3} \mathrm{Mn}_{30} \mathrm{Sn}_{14} \mathrm{In}_{6}$, and $\mathrm{Ni}_{46} \mathrm{Fe}_{4} \mathrm{Mn}_{30-}$ $\mathrm{Sn}_{12} \mathrm{In}_{8}$, respectively).

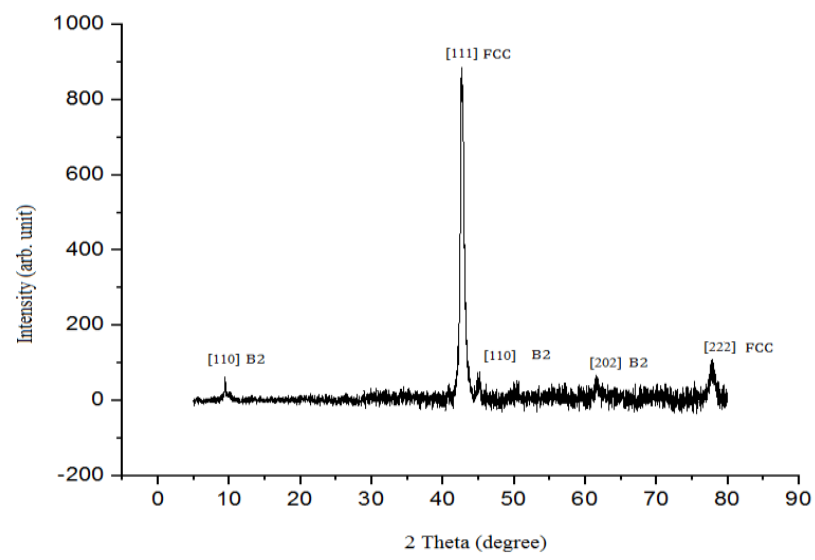

Fig. 3 X-ray diffraction patterns of the $\mathrm{Ni}_{50-\mathrm{x}} \mathrm{Fe}_{\mathrm{x}} \mathrm{Mn}_{30} \mathrm{Sn}_{20-\mathrm{y}} \mathrm{In}_{\mathrm{y}}$ alloy with various phases formed at the highest $\mathrm{Fe}$ concertation.

\subsection{Mechanical properties}

Heusler alloys based on Ni-Mn-Sn are known to be extremely brittle. Due to this critical feature, its applicability is limited to areas under room temperature conditions. To assess the material's brittleness, a compressive test was performed in a universal testing machine (UTM) with the length-to-diameter ratio of the test sample being less than 1.5 , as a greater ratio results in findings that are erroneous. Fig. 4 shows the stressstrain curve under compressive load. The ultimate strength (US) of the Heusler alloy increases from 374 to $837 \mathrm{MPa}$ with the addition of $\mathrm{Fe}_{4}$.

The results of the test are shown in Table 2; it can be observed that when the $\mathrm{Fe}$ content increases from 1 to 4 , the ductility and US of the specimen tend to rise i.e., 200 and $124 \%$, respectively. The area under the curve represents the toughness, i.e., when the $\mathrm{Fe}$ concentration is increased, the toughness is increased by $500 \%$ for maximum substitution $\left(\mathrm{Fe}_{4}\right)$ in comparison to $\mathrm{Fe}_{1}$ as shown in Table 2 where Alloy 1, 2, $3 \& 4$ are $\mathrm{Fe}_{1}, \mathrm{Fe}_{2}, \mathrm{Fe}_{3}$, and $\mathrm{Fe}_{4}$.

Table 2. Increase in stress with the increase in Fe concentration in the alloy.

\begin{tabular}{llll}
\hline Alloy & $\begin{array}{l}\text { Change in } \\
\text { Ultimate Stress }\end{array}$ & $\begin{array}{l}\text { Change in } \\
\text { Ductility at peak }\end{array}$ & $\begin{array}{l}\text { Change in } \\
\text { Toughness w.r.t } \\
\mathrm{Fe}_{1}(\%)\end{array}$ \\
\hline 2 & 44.38 & 50 & 110 \\
3 & 50.51 & 100 & 190 \\
4 & 124 & 200 & 500 \\
\hline
\end{tabular}

The inclusion of $\mathrm{Fe}$ in the alloy in stages 1 to $4 \%$ leads to the formation of the nickel martensite phase. This results in the formation of the FCC phase structure, as shown in the XRD data. This supersaturated phase of Fe-Ni martensitic with an FCC structure possesses exceptional strength and toughness. ${ }^{26}$ This freshly formed face is diametrically opposed to the ironcarbon phase. As the Fe concentration grows in proportion to the Ni concentration during the martensitic transformation, the resulting material has a hexagonal closest-packed (HCP) structure. The addition of $\mathrm{Fe}$ strengthens the supersaturated $\mathrm{Fe}-\mathrm{Ni}$ phase. Further annealing of the specimen precipitates out the intermetallic and other solute-rich phases. The strength grows further as a result of this precipitation. Thus, by adding $\mathrm{Fe}$, the alloy's ductility and the US are increased, enabling it to be used in previously unsuited applications due to the alloy's brittle nature. The ductile phase produced in the alloy as a result of this process limits the fracture propagation at the borders. The energy required to propagate the fracture further increases as the yield strength of the material is increased. As a result, the inclusion of $\mathrm{Fe}$ enhances the ductility, strength, and toughness of the alloy.

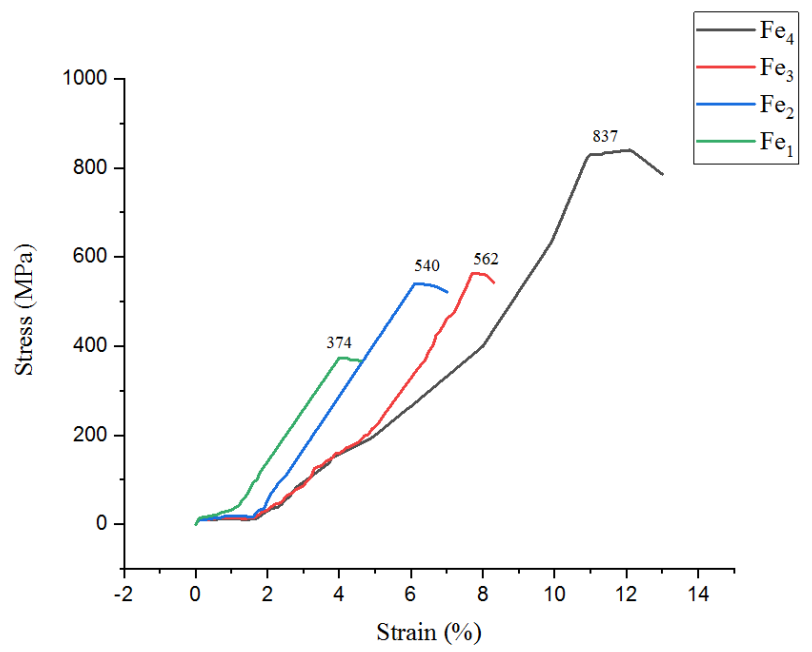

Fig. 4 Compressive stress-strain curve with varying Fe addition.

\subsection{Martensitic transformation (MT)}

According to the findings of the DSC study, heat output ranging from -70 to $+120^{\circ} \mathrm{C}$ was achieved. The findings of 
four different alloys are depicted in Fig. 5. The peak value of by changing the weight $\%$ of iron in the alloy, allowing it to $\mathrm{Ap}$ in the M-A transition is shifted off in the austenite start (As) operate within the temperature range (36.8 to $19.83{ }^{\circ} \mathrm{C}$.) of and austenite finish (Af), resulting in a peak value (Ap) in the M-A transition. The martensitic start (Ms) and finish (Mf) points are denoted in Fig. 5. It appears that the transitions took place above room temperature. One of them is near room temperature, according to the data. ${ }^{[25,27]}$ This is owing to a significant change near the moment of temperature reversal in the measurement, which makes the peaks less prominent. When the cooling and heating data are shown separately, the results are interpreted in the appropriate way. As the Fe content of the alloy increases, the peak height decreases, resulting in a larger zone. The transformation temperatures are depicted in Table 3 .

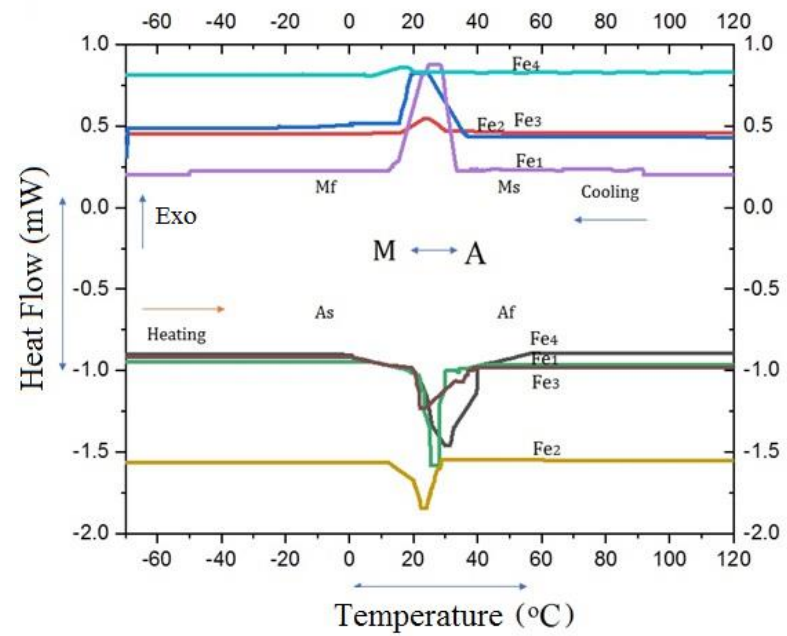

Fig. 5 DSC curves of alloys with variation in Fe substitution.

Table 3. Martensite start-finish and Austenite start-finish temperatures of four sets of alloys.

\begin{tabular}{lllll}
\hline Alloy & $\begin{array}{l}\text { Martensite } \\
\text { Start } \\
\left(\mathrm{Ms} /{ }^{\circ} \mathrm{C}\right)\end{array}$ & $\begin{array}{l}\text { Martensite } \\
\text { Finish } \\
\left(\mathrm{Mf} /{ }^{\circ} \mathrm{C}\right)\end{array}$ & $\begin{array}{l}\text { Austenite } \\
\text { Finish } \\
\left(\mathrm{Af} /{ }^{\circ} \mathrm{C}\right)\end{array}$ & $\begin{array}{l}\text { Austenite } \\
\text { Start } \\
\left(\mathrm{As} /{ }^{\circ} \mathrm{C}\right)\end{array}$ \\
\hline 1 & 36.8 & 15.66 & 12.33 & 38.27 \\
2 & 34.33 & 12.56 & 4.83 & 29.64 \\
3 & 29.83 & 10.83 & 0.66 & 28.42 \\
4 & 19.83 & 5.66 & 0.66 & 27.45 \\
\hline
\end{tabular}

\section{Conclusion}

The Fe content of the Heusler alloy has been effectively increased in order to lower the martensite transition temperature. Dendrites of rougher texture are refined after they have been homogenized. The martensitic transition occurs with the addition of $\mathrm{Fe}$ throughout a large temperature range, ranging from 36.8 to $19.83{ }^{\circ} \mathrm{C}$. It also significantly increased the alloy's compressive strength, which increased from 380 to $850 \mathrm{MPa}$. Comparing the same materials with and without $\mathrm{Fe}$, the US and ductility rise by 124 and $200 \%$, respectively, but toughness increases by 48 times as compared to the same materials with and without $\mathrm{Fe}$ addition. It is possible to adjust the martensitic transformation of the alloy refrigerator applications. Thus, scaling up of the alloys formed can be used for suitable magnetic refrigeration systems.

\section{Acknowledgment}

This work was carried out by making use of facilities at the Indian Institute of Science (IISC, Bengaluru, India) and Defence Metallurgical Research Laboratory, Hyderabad, India.

\section{Conflict of interest}

There are no conflicts to declare.

\section{Supporting information}

Applicable.

\section{References}

[1] S. A. Montzka, G. S. Dutton, P. Yu, E. Ray, R. W. Portmann, J. S. Daniel, L. Kuijpers, B. D. Hall, D. Mondeel, C. Siso, J. David Nance, M. Rigby, A. J. Manning, L. Hu, F. Moore, B. R. Miller, J. W. Elkins, Nature, 2018, 557, 413-417, doi: 10.1038/s41586-018-0106-2.

[2] A. K. Gschneidner, K. V. Pecharsky, International Journal of Refrigeration, 2010, 3, 645-647, doi: 10.1016/j.ijrefrig.2009.11.001.

[3] F. Heusler, E. Take, Transactions of the Faraday Society, 1912 8, 169-184, doi: 10.1039/TF9120800169.

[4] P. J. Webster, K. R. A. Ziebeck, S. L. Town, M. S. Peak, Philosophical Magazine B, 1984, 49, 295-310, doi: $10.1080 / 13642817408246515$.

[5] T. Krenke, E. Duman, M. Acet, E. F. Wassermann, X. Moya, L. Mañosa, A. Planes, E. Suard, B. Ouladdiaf, Physical Review B, 2006, 75, 104414, doi: 1103/PhysRevB.75.104414.

[6] H. Zhang, X. Zhang, M. Qian, L. Wei, D. Xing, J. Sun, L. Geng, Journal of Alloys and Compounds, 2017, 715, 206-213, doi 10.1016/j.jallcom.2017.04.277.

[7] H. Zhang, M. Qian, X. Zhang, L. Wei, F. Cao, D. Xing, X. Cui, J. Sun, L. Geng, Journal of Alloys and Compounds, 2016, 689, doi: 10.1016/j.jallcom.2016.07.282.

[8] Z. Wu, J. Guo, Z. Liang, Y. Zhang, X. Ye, J. Zhang, Y. Li, Y. Liu, H. Yang, Journal of Alloys and Compounds, 2020, 842, 455457, doi: 10.1016/j.jallcom.2020.155977.

[9] D. Salazar, V.A. Chernenko, Acta Materialia, 2016, 107, 9-16, doi: 10.1016/j.actamat.2016.01.041.

[10] G. R. Raji, B. Uthaman, R. B. Job, S. Thomas, K. G. Suresh, M. R. Varma, Intermetallics, 2018, 100, 116-125, doi: 10.1016/j.intermet.2018.06.003.

[11] X. G., M. Tong Zhao, C. W. Shih, W. C. Chang, W. Liu, Z. D. Zhang, IEEE Transactions on Magnetics, 2014, 50, http://ir.imr.ac.cn/handle/321006/74037.

[12] K. Fukushima, K. Sano, T. Kanomata, H. Nishihara, Y. Furutani, T. Shishido, W. Ito, R. Y. Umetsu, R. Kainuma, K. Oikawa, K. Ishida, Scripta Materialia, 2009, 61, 813-816, doi: 10.1016/j.scriptamat.2009.07.003.

[13] G. Kirat, M. A. Aksan, Y. Aydogdu, Intermetallics, 2019, 111, 
106493, doi: 10.1016/j.intermet.2019.106493.

[14] F. Q. Li, Y. H. Qu, H. L. Yan, Z. Chen, D. Y. Cong, X. M. Sun, S. H. Li, Y. D. Wang, Applied Physics Letters, 2018, 113, 112402, doi: 10.1063/1.5045834.

[15] R. Modak, V. V. Srinivasu, A. Srinivasan, Journal of Magnetism and Magnetic Materials, 2018, 464, 50-55, doi: 10.1016/j.jmmm.2018.05.050.

[16] X. Tian, Z. Wang, J. Zhu, C. Tan, K. Zhang, Z. Yu, W. Cai, Journal of Non-Crystalline Solids, 2018, 495, 19-26, doi: 10.1016/j.jnoncrysol.2018.05.008.

[17] H. Zhang, X. Zhang, M. Qian, B. Yuan, L. Geng, Intermetallics, 2019, 105, 124-129, doi: 10.1016/j.intermet.2018.11.014.

[18] Y. Zhang, J. Liu, Q. Zheng, J. Zhang, W. Xia, J. Du, A. Yan, Scripta Materialia, 2014, 75, 26-29, doi: 10.1016/j.scriptamat.2013.11.009.

[19] C.-L. Tan, Z.-C. Feng, K. Zhang, M.-Y. Wu, X.-H. Tian, E.J. Guo, Transactions of Nonferrous Metals Society of China, 2017, 27, 2234-2238, doi: 10.1016/s1003-6326(17)60249-8.

[20] E.C. Passamani, F. Xavier, C. Larica, A.Y. Takeuchi, I.L. Castro, J. R. Proveti, Journal of Alloys and Compounds, 2013, 628, 164-169, doi: 10.1016/j.jallcom.2014.12.192.

[21] Z. Wu, J. Guo, Z. Liang, Y. Zhang, X. Ye, Journal of Alloys and Compounds, 2020, 829, 154606 doi: 10.1016/j.jallcom.2020.154606.

[22] Z. Wu, J. Guo, Z. Liang, Y. Zhang, X. Ye, J. Zhang, Y. Li, Y. Liu, H. Yang, Journal of Alloys and Compounds, 2020, 829, 154606, doi: 10.1016/j.jallcom.2020.154606.

[23] J. Guo, M. Zhong, W. Zhou, Y. Zhang, Z. Wu, Y. Li, J. Zhang, Y. Liu, H. Yang, Materials, 2021, 14, 2339, doi: 10.3390/ma14092339.

[24] A. Bonda, S. Uba, L. Uba, Dubowik, Journal of Magnetism and Magnetic Materials, 2020, 504, 166686, doi: 10.1016/j.jmmm.2020.166686.

[25] D. Pal, Journal of Scientific Research, 2020, 12, 303-310, doi: 10.3329/jsr.v12i3.44357.

[26] S. H. Avner, University of New York, 1974, 2, 481-497.

[27] A. Deltell, A. El-Moez A Mohamed, P. Álvarez-Alonso, M. Ipatov, J. P. Andrés, J. A. González, T. Sánchez, A. Zhukov, M. L. Escoda, J. J. Suñol, R. López Antón, Journal of Materials Research and Technology, 2021, 12, 1091-1103, doi: 10.1016/j.jmrt.2021.03.049.

\section{Author Information}

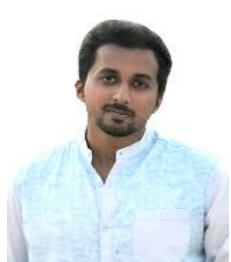

Sandeep Nambiar S., is currently completing his PhD on Heusler alloys and his area of interest are in $\mathrm{Ni}-\mathrm{Mn}$ based heusler alloys, Al based metal matrix composite, machining of composites and its heat treatment. He has completed his Maters in Manufacturing Engineering and Technology at Manipal Institute of Technology, Manipal Academy of Higher Education, Manipal, India.
BRN. Murthy is currently working as Associate Professor- Senior Scale, Department of Mechanical and Manufacturing Engineering, Manipal Institute of Technology, Manipal Academy of Higher Education, Manipal, India. He is the author for several articles in various International Journals. His research includes optimisation and simulation of machining process on various types of fiber re-in forced polymer composites through Taguchi, Response Surface Methodology, Artificial Neural Networks and System Dynamic Methods. His field of research also includes conduction of Austmepring heat treatment to improve the performance of Austempered Ductile Iron Balls which are recognised as the better grinding media for grinding iron ores in ball mills. Currently he is working on many projects.

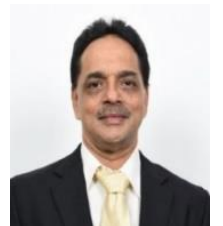

Sathyashankara Sharma is currently the Professor and Head at Department of Mechanical \& Manufacturing Engineering, Manipal Academy of Higher Education, Manipal. His area of interest includes manufacturing engineering and materials engineering. His area of expertise heat treatment of metals, alloys and composites. He has over 100 research articles published in international journals.

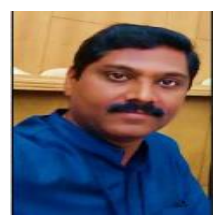

A. A. Prasanna is currently working as associate professor of physics at Malnad College of Engineering, Hassan, Karnataka (India). He is serving in the academic domain since 24 years. He obtained his masters degree in physics from the university of Mysore, Karnataka, and Ph. D. from IIT, Kharagpur, West Bengal, India. His field of interest is materials science. He is working on magnetic refrigerant materials. He has published 30 research articles in national and international journals and conference proceedings

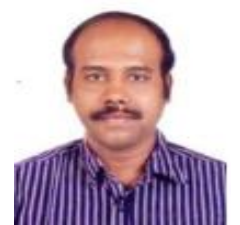

Arout Chelvane J. received his Ph. D. (Physics) from IIT Madras, Chennai during 2005. He is currently working as Scientist in the Advanced Magnetics Group, Defence Metallurgical Research Laboratory, Hyderabad, India. His current area of research interest is in evolving structure-process-property correlations in rare earth based magnetic materials (bulk and thin films).

Publisher's Note: Engineered Science Publisher remains neutral with regard to jurisdictional claims in published maps and institutional affiliations. 